Supporting Information for

\title{
Spatially resolved analysis of Pseudomonas aeruginosa biofilm proteomes measured by laser ablation sample transfer
}

\author{
Aruni Chathurya Pulukkody, ${ }^{1}$ Yeni P. Yung, ${ }^{1}$ Fabrizio Donnarumma, ${ }^{2}$ Kermit K. Murray ${ }^{2}$, \\ Ross P. Carlson, ${ }^{3}$ and Luke Hanley ${ }^{1, *}$ \\ ${ }^{1}$ Department of Chemistry, University of Illinois at Chicago, Chicago, IL 60607, USA \\ ${ }^{2}$ Department of Chemistry, Louisiana State University, 232 Choppin Hall, Baton Rouge, LA \\ 70803, USA
}

${ }^{3}$ Department of Chemical and Biological Engineering, Center for Biofilm Engineering, Montana State University, Bozeman, MT 59717
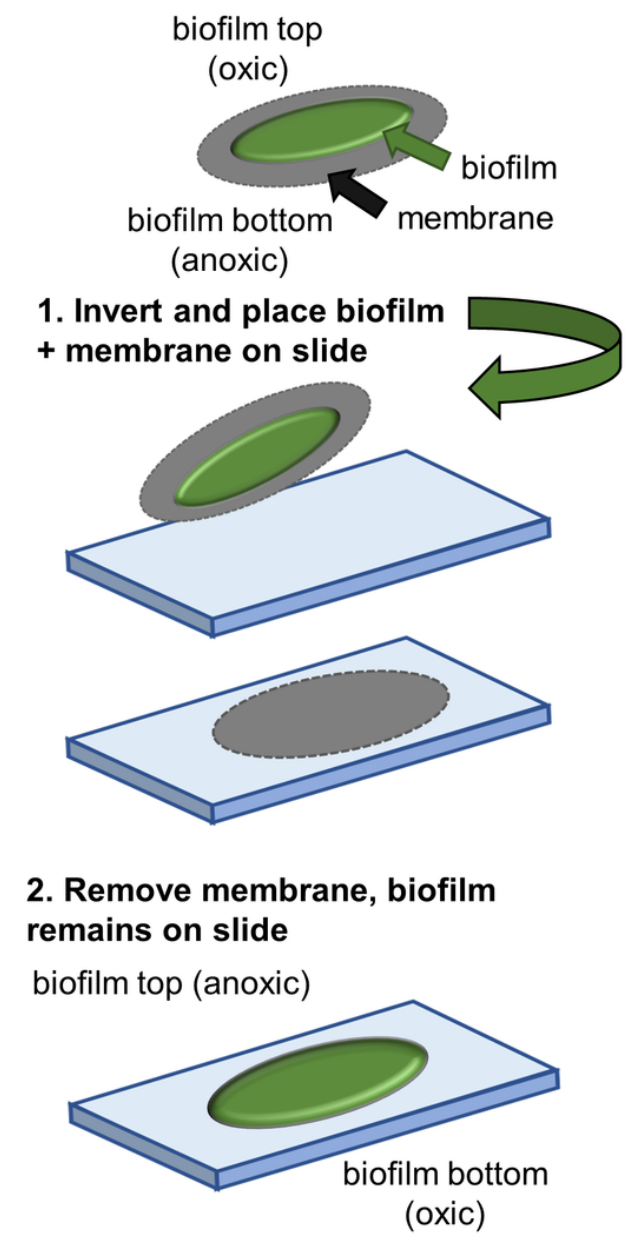

S1 Fig. Strategy for exposing anaerobic surface of a biofilm. Process involved freezing the membrane on dry ice and inversion on a glass slide. The membrane was peeled off the glass slide to expose the anoxic side of the biofilm. 
S1 Table: $P$. aeruginosa proteins identified from three-day biofilms grown on polycarbonate membranes. Proteins in brown font correspond to those that appear only in older cell region (1 $\mathrm{mm}$ square, brown region in Fig 5A) while proteins in green font appear only in newer cell region of biofilm ( $2 \mathrm{~mm}$ square, green region in Fig 5A). Black proteins are common to both regions. All reported proteins displayed at least two unique peptides and $\geq 10 \%$ sequence coverage. Data is preliminary as it was collected from only one pooled LC-MS/MS analysis each, so no statistical analysis was possible.

\begin{tabular}{|c|c|c|c|c|}
\hline Protein & $\begin{array}{c}\text { KEGG } \\
\text { ID }\end{array}$ & Description of Protein & $\begin{array}{c}\text { Unique } \\
\text { Peptides }\end{array}$ & $\begin{array}{c}\text { Sequence } \\
\text { Coverage } \\
\text { (\%) }\end{array}$ \\
\hline DapA & PA1010 & Dihydrodipicolinate synthase & 2 & 10 \\
\hline RplS & PA3742 & 50S ribosomal protein L19 & 2 & 31 \\
\hline RibH & PA4053 & $\begin{array}{c}\text { 6,7-dimethyl-8-ribityllumazine } \\
\text { synthase }\end{array}$ & 2 & 15 \\
\hline RplN & PA4253 & 50S ribosomal protein L14 & 5 & 40 \\
\hline RplV & PA4258 & 50S ribosomal protein L22 & 2 & 28 \\
\hline RpsJ & PA4264 & 30S ribosomal protein S10 & 2 & 23 \\
\hline RpsL & PA4268 & 30S ribosomal protein S12 & 2 & 15 \\
\hline AtpA & PA5556 & ATP synthase alpha chain & 2 & 34 \\
\hline MetK & PA4546 & Methionine adenosyltransferase & 8 & 26 \\
\hline Pgk & PA0552 & Phosphoglycerate kinase & 5 & 16 \\
\hline TufA;TufB & PA4265 & Elongation factor Tu & 12 & 64 \\
\hline RplK & PA4274 & 50S ribosomal protein L11 & 7 & 57 \\
\hline RplA & PA4273 & 50S ribosomal protein L1 & 9 & 50 \\
\hline RplJ & PA4272 & 50S ribosomal protein L10 & 5 & 39 \\
\hline RpsG & PA4267 & 30S ribosomal protein S7 & 6 & 37 \\
\hline RplC & PA4263 & 50S ribosomal protein L3 & 5 & 27 \\
\hline RplD & PA4262 & 50S ribosomal protein L4 & 5 & 24 \\
\hline RplW & PA4261 & 50S ribosomal protein L23 & 2 & 19 \\
\hline RplB & PA4260 & 50S ribosomal protein L2 & 5 & 21 \\
\hline RpsC & PA4257 & 30S ribosomal protein S3 & 6 & 40 \\
\hline RplP & PA4256 & 50S ribosomal protein L16 & 3 & 23 \\
\hline Rp1X & PA4252 & 50S ribosomal protein L24 & 3 & 36 \\
\hline RpsN & PA4250 & 30S ribosomal protein S14 & 2 & 22 \\
\hline RpsH & PA4249 & 30S ribosomal protein S8 & 3 & 25 \\
\hline RplR & PA4247 & 50S ribosomal protein L18 & 5 & 31 \\
\hline RpsE & PA4246 & 30S ribosomal protein S5 & 5 & 41 \\
\hline Rp1O & PA4244 & 50S ribosomal protein L15 & 6 & 45 \\
\hline RpsK & PA4240 & 30S ribosomal protein S11 & 3 & 24 \\
\hline & & & & \\
\hline
\end{tabular}




\begin{tabular}{|c|c|c|c|c|}
\hline RpoA & PA4238 & $\begin{array}{c}\text { DNA-directed RNA polymerase } \\
\text { alpha chain }\end{array}$ & 8 & 23 \\
\hline HemL & PA3977 & $\begin{array}{l}\text { Glutamate- } 1 \text {-semialdehyde } 2,1 \text { - } \\
\text { aminomutase }\end{array}$ & 4 & 16 \\
\hline Ndk & PA3807 & Nucleoside diphosphate kinase & 4 & 28 \\
\hline $\mathrm{R} \operatorname{lm} \mathrm{N}$ & PA3806 & $\begin{array}{c}\text { Dual-specificity RNA } \\
\text { methyltransferase RlmN }\end{array}$ & 3 & 12 \\
\hline RplS & PA3742 & 50S ribosomal protein L19 & 4 & 50 \\
\hline Tsf & PA3655 & Elongation factor Ts & 7 & 25 \\
\hline PyrG & PA3637 & CTP synthase & 6 & 12 \\
\hline Eno & PA3635 & Enolase & 4 & 13 \\
\hline RecA & PA3617 & Protein RecA & 8 & 30 \\
\hline FadB & PA3014 & $\begin{array}{l}\text { Fatty acid oxidation complex } \\
\text { subunit alpha } \\
\end{array}$ & 7 & 15 \\
\hline SthA & PA2991 & $\begin{array}{c}\text { Soluble pyridine nucleotide } \\
\text { transhydrogenase }\end{array}$ & 7 & 24 \\
\hline Efp & PA2851 & Elongation factor $\mathrm{P}$ & 3 & 22 \\
\hline RplT & PA2741 & 50S ribosomal protein L20 & 4 & 24 \\
\hline NuoA2 & PA2637 & $\begin{array}{c}\text { NADH-quinone oxidoreductase } \\
\text { subunit A } 2\end{array}$ & 2 & 20 \\
\hline ClpX & PA1802 & $\begin{array}{l}\text { ATP-dependent Clp protease ATP- } \\
\text { binding subunit ClpX }\end{array}$ & 4 & 11 \\
\hline FabA & PA1610 & $\begin{array}{l}\text { 3-hydroxydecanoyl-[acyl-carrier- } \\
\text { protein] dehydratase }\end{array}$ & 2 & 12 \\
\hline SucC & PA1588 & $\begin{array}{l}\text { Succinate--CoA ligase [ADP- } \\
\text { forming] subunit beta }\end{array}$ & 10 & 53 \\
\hline ProS & PA0956 & Proline--tRNA ligase & 6 & 12 \\
\hline $\mathrm{PhhB}$ & PA0871 & $\begin{array}{c}\text { Pterin-4-alpha-carbinolamine } \\
\text { dehydratase }\end{array}$ & 4 & 36 \\
\hline GroES & PA4386 & $10 \mathrm{kDa}$ chaperonin & 4 & 50 \\
\hline LpxC & PA4406 & $\begin{array}{c}\text { UDP-3-O-acyl-N- } \\
\text { acetylglucosamine deacetylase }\end{array}$ & 7 & 27 \\
\hline RpsI & PA4432 & 30S ribosomal protein S9 & 5 & 37 \\
\hline MurA & PA4450 & $\begin{array}{l}\text { UDP-N-acetylglucosamine 1- } \\
\text { carboxyvinyltransferase }\end{array}$ & 6 & 17 \\
\hline $\mathrm{MscL}$ & PA4614 & $\begin{array}{l}\text { Large-conductance } \\
\text { mechanosensitive channel }\end{array}$ & 2 & 16 \\
\hline IlvC & PA4694 & $\begin{array}{l}\text { Ketol-acid reductoisomerase } \\
(\mathrm{NADP}(+))\end{array}$ & 9 & 34 \\
\hline InfB & PA4744 & Translation initiation factor IF-2 & 5 & 11 \\
\hline DapB & PA4759 & $\begin{array}{l}\text { 4-hydroxy-tetrahydrodipicolinate } \\
\text { reductase }\end{array}$ & 2 & 11 \\
\hline PurH & PA4854 & $\begin{array}{c}\text { Bifunctional purine biosynthesis } \\
\text { protein PurH }\end{array}$ & 6 & 13 \\
\hline
\end{tabular}




\begin{tabular}{|c|c|c|c|c|}
\hline RplI & PA4932 & 50S ribosomal protein L9 & 4 & 32 \\
\hline RpsF & PA4935 & 30S ribosomal protein S6 & 4 & 27 \\
\hline PurA & PA4938 & Adenylosuccinate synthetase & 4 & 11 \\
\hline HslU & PA5054 & $\begin{array}{l}\text { ATP-dependent protease ATPase } \\
\text { subunit HslU }\end{array}$ & 6 & 13 \\
\hline SecB & PA5128 & Protein-export protein SecB & 2 & 10 \\
\hline PckA & PA5192 & $\begin{array}{l}\text { Phosphoenolpyruvate } \\
\text { carboxykinase (ATP) }\end{array}$ & 7 & 16 \\
\hline RpmB & PA5316 & 50S ribosomal protein L28 & 3 & 40 \\
\hline AtpC & PA5553 & ATP synthase epsilon chain & 3 & 25 \\
\hline AtpD & PA5554 & ATP synthase subunit beta & 21 & 63 \\
\hline AtpG & PA5555 & ATP synthase gamma chain & 4 & 19 \\
\hline AtpA & PA5556 & ATP synthase subunit alpha & 4 & 38 \\
\hline YidC & PA5568 & Membrane protein insertase YidC & 6 & 13 \\
\hline PepA & PA3831 & Cytosol aminopeptidase & 9 & 24 \\
\hline IscS & PA3814 & Cysteine desulfurase IscS & 4 & 11 \\
\hline GuaA & PA3769 & $\begin{array}{l}\text { GMP synthase [glutamine- } \\
\text { hydrolyzing] }\end{array}$ & 7 & 15 \\
\hline AspS & PA0963 & Aspartate--tRNA(Asp/Asn) ligase & 7 & 22 \\
\hline AstB & PA0899 & N-succinylarginine dihydrolase & 6 & 17 \\
\hline GroEL & PA4385 & $60 \mathrm{kDa}$ chaperonin & 28 & 48 \\
\hline $\operatorname{Sec} \mathrm{A}$ & PA4403 & Protein translocase subunit SecA & 14 & 18 \\
\hline Eco & PA2755 & Ecotin & 2 & 12 \\
\hline GatA & PA4483 & $\begin{array}{l}\text { Glutamyl-tRNA(Gln) } \\
\text { amidotransferase subunit A }\end{array}$ & 6 & 15 \\
\hline RplU & PA4568 & 50S ribosomal protein L21 & 8 & 70 \\
\hline RplY & PA4671 & 50S ribosomal protein L25 & 7 & 56 \\
\hline GlyS & PA0008 & Glycine--tRNA ligase beta subunit & 8 & 13 \\
\hline ThrS & PA2744 & Threonine--tRNA ligase & 7 & 11 \\
\hline Pnp & PA4740 & $\begin{array}{c}\text { Polyribonucleotide } \\
\text { nucleotidyltransferase }\end{array}$ & 23 & 37 \\
\hline GlmM & PA4749 & Phosphoglucosamine mutase & 4 & 10 \\
\hline DnaJ & PA4760 & Chaperone protein DnaJ & 7 & 31 \\
\hline CoaD & PA0363 & $\begin{array}{l}\text { Phosphopantetheine } \\
\text { adenylyltransferase }\end{array}$ & 3 & 23 \\
\hline ArgS & PA5051 & Arginine--tRNA ligase & 6 & 11 \\
\hline HutU & PA5100 & Urocanate hydratase & 8 & 17 \\
\hline AhcY & PA0432 & Adenosylhomocysteinase & 5 & 13 \\
\hline LptD & PA0595 & LPS-assembly protein LptD & 2 & 12 \\
\hline RpoB & PA4270 & $\begin{array}{c}\text { DNA-directed RNA polymerase } \\
\text { subunit beta }\end{array}$ & 40 & 35 \\
\hline
\end{tabular}




\begin{tabular}{|c|c|c|c|c|}
\hline RplE & PA4251 & 50S ribosomal protein L5 & 6 & 37 \\
\hline RpsM & PA4241 & 30S ribosomal protein $\mathrm{S} 13$ & 7 & 52 \\
\hline RpsD & PA4239 & 30 S ribosomal protein $\mathrm{S} 4$ & 6 & 32 \\
\hline RpsB & PA3656 & 30 S ribosomal protein $\mathrm{S} 2$ & 6 & 18 \\
\hline $\mathrm{RdgC}$ & PA3263 & $\begin{array}{c}\text { Recombination-associated protein } \\
\text { RdgC }\end{array}$ & 3 & 12 \\
\hline SerC & PA3167 & Phosphoserine aminotransferase & 6 & 19 \\
\hline Tig & PA1800 & Trigger factor & 14 & 42 \\
\hline CysS & PA1795 & Cysteine--tRNA ligase & 4 & 11 \\
\hline PctA & PA4309 & $\begin{array}{l}\text { Methyl-accepting chemotaxis } \\
\text { protein PctA }\end{array}$ & 3 & 24 \\
\hline DapD & PA3666 & $\begin{array}{c}\text { 2,3,4,5-tetrahydropyridine-2,6- } \\
\text { dicarboxylate N-succinyltransferase }\end{array}$ & 4 & 13 \\
\hline AruC & PA0895 & $\begin{array}{l}\text { Succinylornithine } \\
\text { transaminase/acetylornithine } \\
\text { aminotransferase }\end{array}$ & 6 & 21 \\
\hline EstA & PA5112 & Esterase EstA & 6 & 13 \\
\hline KatA & PA4236 & Catalase & 9 & 25 \\
\hline Zwf & PA3183 & $\begin{array}{c}\text { Glucose-6-phosphate 1- } \\
\text { dehydrogenase }\end{array}$ & 8 & 23 \\
\hline RatA & PA4767 & Ribosome association toxin RatA & 2 & 13 \\
\hline LysC & PA0904 & Aspartokinase & 5 & 14 \\
\hline HupB & PA1804 & DNA-binding protein HU-beta & 2 & 32 \\
\hline ArcB & PA5172 & $\begin{array}{c}\text { Ornithine carbamoyltransferase, } \\
\text { catabolic }\end{array}$ & 12 & 31 \\
\hline OprI & PA2853 & Major outer membrane lipoprotein & 4 & 39 \\
\hline OprF & PA1777 & Outer membrane porin $\mathrm{F}$ & 14 & 41 \\
\hline ArcA & PA5171 & Arginine deiminase & 13 & 35 \\
\hline GltA & PA1580 & Citrate synthase & 9 & 16 \\
\hline $\mathrm{BraC}$ & PA1074 & $\begin{array}{l}\text { Leucine-, isoleucine-, valine-, } \\
\text { threonine-, and alanine-binding } \\
\text { protein }\end{array}$ & 12 & 42 \\
\hline FliC & PA1092 & B-type flagellin & 16 & 46 \\
\hline $\mathrm{BraF}$ & PA1071 & $\begin{array}{l}\text { High-affinity branched-chain amino } \\
\text { acid transport protein BraF }\end{array}$ & 3 & 15 \\
\hline Gor & PA2025 & Glutathione reductase & 4 & 12 \\
\hline $\mathrm{AlgC}$ & PA5322 & $\begin{array}{l}\text { Phosphomannomutase/phosphogluc } \\
\text { omutase }\end{array}$ & 9 & 24 \\
\hline Gap & PA3195 & $\begin{array}{l}\text { Glyceraldehyde-3-phosphate } \\
\text { dehydrogenase }\end{array}$ & 9 & 36 \\
\hline Edd & PA3194 & Phosphogluconate dehydratase & 8 & 18 \\
\hline OprD & PA0958 & Porin D & 11 & 29 \\
\hline
\end{tabular}




\begin{tabular}{|c|c|c|c|c|}
\hline BamD & PA4545 & $\begin{array}{l}\text { Outer membrane protein assembly } \\
\text { factor BamD }\end{array}$ & 7 & 20 \\
\hline OprF & PA1777 & Outer membrane porin F & 3 & 10 \\
\hline $\mathrm{AccC}$ & PA4848 & Biotin carboxylase & 6 & 21 \\
\hline $\mathrm{Ssb}$ & PA4232 & $\begin{array}{l}\text { Single-stranded DNA-binding } \\
\text { protein }\end{array}$ & 2 & 14 \\
\hline PilJ & PA0411 & Protein PilJ & 11 & 24 \\
\hline $\mathrm{PhhC}$ & PA0870 & $\begin{array}{c}\text { Aromatic-amino-acid } \\
\text { aminotransferase }\end{array}$ & 6 & 19 \\
\hline PilG & PA0408 & Protein PilG & 2 & 18 \\
\hline FtsA & PA4408 & Cell division protein FtsA & 4 & 13 \\
\hline FtsZ & PA4407 & Cell division protein FtsZ & 6 & 20 \\
\hline TolQ & PA0969 & Tol-Pal system protein TolQ & 2 & 11 \\
\hline TolR & PA0970 & Tol-Pal system protein TolR & 4 & 37 \\
\hline TolB & PA0972 & Tol-Pal system protein TolB & 9 & 27 \\
\hline MexB & PA0426 & Multidrug resistance protein MexB & 14 & 19 \\
\hline MexA & PA0425 & Multidrug resistance protein MexA & 11 & 36 \\
\hline SodB & PA4366 & Superoxide dismutase $[\mathrm{Fe}]$ & 2 & 14 \\
\hline AspC & PA3139 & Aspartate aminotransferase & 3 & 10 \\
\hline HemN & PA1546 & $\begin{array}{c}\text { Oxygen-independent } \\
\text { coproporphyrinogen III oxidase }\end{array}$ & 4 & 10 \\
\hline XcpT & PA3101 & $\begin{array}{c}\text { Type II secretion system core } \\
\text { protein } G\end{array}$ & 2 & 16 \\
\hline AtpF & PA5558 & ATP synthase subunit b & 9 & 44 \\
\hline DnaK & PA4761 & Chaperone protein DnaK & 28 & 59 \\
\hline IleS & PA4560 & Isoleucine--tRNA ligase & 10 & 13 \\
\hline AlaS & PA0903 & Alanine--tRNA ligase & 9 & 13 \\
\hline PpsA & PA1770 & Phosphoenolpyruvate synthase & 10 & 16 \\
\hline Icd & PA2623 & Isocitrate dehydrogenase [NADP] & 12 & 31 \\
\hline NuoC & PA2639 & $\begin{array}{l}\text { NADH-quinone oxidoreductase } \\
\text { subunit C/D }\end{array}$ & 11 & 21 \\
\hline Tal & PA2796 & Transaldolase & 4 & 16 \\
\hline NqrA & PA2999 & $\begin{array}{l}\mathrm{Na}(+) \text {-translocating } \mathrm{NADH}- \\
\text { quinone reductase subunit } \mathrm{A}\end{array}$ & 8 & 23 \\
\hline GltX & PA3134 & Glutamate--tRNA ligase & 6 & 12 \\
\hline LysS & PA3700 & Lysine--tRNA ligase & 11 & 28 \\
\hline $\mathrm{RpoC}$ & PA4269 & $\begin{array}{c}\text { DNA-directed RNA polymerase } \\
\text { subunit beta' }\end{array}$ & 33 & 27 \\
\hline SpuD & PA0300 & $\begin{array}{l}\text { Putrescine-binding periplasmic } \\
\text { protein SpuD }\end{array}$ & 7 & 25 \\
\hline AhpC & PA0139 & Alkyl hydroperoxide reductase $\mathrm{C}$ & 5 & 33 \\
\hline Fur & PA4764 & Ferric uptake regulation protein & 3 & 27 \\
\hline
\end{tabular}




\begin{tabular}{|c|c|c|c|c|}
\hline MrcA & PA5045 & Penicillin-binding protein $1 \mathrm{~A}$ & 10 & 14 \\
\hline PurF & PA3108 & Amidophosphoribosyltransferase & 5 & 11 \\
\hline NirF & PA0516 & Protein NirF & 5 & 15 \\
\hline OprB & PA3186 & Porin B & 15 & 41 \\
\hline OprM & PA0427 & Outer membrane protein OprM & 19 & 48 \\
\hline SucD & PA1589 & $\begin{array}{l}\text { Succinate--CoA ligase [ADP- } \\
\text { forming] subunit alpha }\end{array}$ & 10 & 39 \\
\hline AceE & PA5015 & $\begin{array}{l}\text { Pyruvate dehydrogenase E1 } \\
\text { component }\end{array}$ & 28 & 31 \\
\hline AceF & PA5016 & $\begin{array}{l}\text { Dihydrolipoamide acetyltransferase } \\
\text { component of pyuruvate } \\
\text { dehydrogenase complex }\end{array}$ & 13 & 33 \\
\hline HemB & PA5243 & $\begin{array}{c}\text { Delta-aminolevulinic acid } \\
\text { dehydratase }\end{array}$ & 6 & 21 \\
\hline Rho & PA5239 & $\begin{array}{c}\text { Transcription termination factor } \\
\text { Rho }\end{array}$ & 6 & 19 \\
\hline FabY & PA5174 & $\begin{array}{c}\text { Beta-ketoacyl-[acyl-carrier-protein] } \\
\text { synthase FabY }\end{array}$ & 5 & 12 \\
\hline GpmI & PA5131 & $\begin{array}{c}\text { 2,3-bisphosphoglycerate- } \\
\text { independent phosphoglycerate } \\
\text { mutase }\end{array}$ & 6 & 15 \\
\hline $\mathrm{G} \ln \mathrm{A}$ & PA5119 & Glutamine synthetase & 8 & 19 \\
\hline PurD & PA4855 & $\begin{array}{c}\text { Phosphoribosylamine--glycine } \\
\text { ligase }\end{array}$ & 7 & 23 \\
\hline Prs & PA4670 & $\begin{array}{c}\text { Ribose-phosphate } \\
\text { pyrophosphokinase }\end{array}$ & 7 & 32 \\
\hline PagL & PA4661 & Lipid A deacylase PagL & 5 & 33 \\
\hline GlyA2 & PA4602 & Serine hydroxymethyltransferase 3 & 5 & 15 \\
\hline ClpB & PA4542 & Chaperone protein $\mathrm{ClpB}$ & 15 & 23 \\
\hline FusA & PA4266 & Elongation factor $\mathrm{G} 1$ & 26 & 49 \\
\hline PA3922 & PA3922 & Uncharacterized protein PA3922 & 11 & 33 \\
\hline SecD & PA3821 & Protein translocase subunit SecD & 7 & 12 \\
\hline BamB & PA3800 & $\begin{array}{l}\text { Outer membrane protein assembly } \\
\text { factor BamB }\end{array}$ & 8 & 23 \\
\hline RpsA & PA3162 & $30 \mathrm{~S}$ ribosomal protein $\mathrm{S} 1$ & 13 & 31 \\
\hline GdhB & PA3068 & $\begin{array}{c}\text { NAD-specific glutamate } \\
\text { dehydrogenase }\end{array}$ & 26 & 19 \\
\hline PA2953 & PA2953 & $\begin{array}{l}\text { Electron transfer flavoprotein- } \\
\text { ubiquinone oxidoreductase }\end{array}$ & 9 & 22 \\
\hline EtfB & PA2952 & $\begin{array}{l}\text { Electron transfer flavoprotein } \\
\text { subunit beta }\end{array}$ & 3 & 18 \\
\hline PA2652 & PA2652 & $\begin{array}{l}\text { Methyl-accepting chemotaxis } \\
\text { protein PA2652 }\end{array}$ & 4 & 12 \\
\hline
\end{tabular}




\begin{tabular}{|c|c|c|c|c|}
\hline PurB & PA2629 & Adenylosuccinate lyase & 6 & 16 \\
\hline ClpP1 & PA1801 & $\begin{array}{l}\text { ATP-dependent Clp protease } \\
\text { proteolytic subunit } 1\end{array}$ & 2 & 15 \\
\hline AcnB & PA1787 & Aconitate hydratase B & 23 & 34 \\
\hline PA1618 & PA1618 & Putative esterase PA1618 & 2 & 17 \\
\hline HtpG & PA1596 & Chaperone protein HtpG & 15 & 30 \\
\hline LpdG & PA1587 & Dihydrolipoyl dehydrogenase & 15 & 42 \\
\hline SucB & PA1586 & $\begin{array}{l}\text { Dihydrolipoamide } \\
\text { succinyltransferase (E2 subunit) }\end{array}$ & 13 & 41 \\
\hline $\mathrm{CcmH}$ & PA1482 & $\begin{array}{c}\text { Cytochrome c-type biogenesis } \\
\text { protein } \mathrm{CcmH}\end{array}$ & 2 & 14 \\
\hline AnsB & PA1337 & Glutaminase-asparaginase & 6 & 27 \\
\hline Pal & PA0973 & $\begin{array}{l}\text { Peptidoglycan-associated } \\
\text { lipoprotein }\end{array}$ & 3 & 23 \\
\hline AcsA1 & PA0887 & Acetyl-coenzyme A synthetase 1 & 7 & 15 \\
\hline MliC & PA0867 & $\begin{array}{l}\text { Membrane-bound lysozyme } \\
\text { inhibitor of C-type lysozyme }\end{array}$ & 5 & 44 \\
\hline $\mathrm{Hpd}$ & PA0865 & $\begin{array}{l}\text { 4-hydroxyphenylpyruvate } \\
\text { dioxygenase }\end{array}$ & 15 & 47 \\
\hline FumC1 & PA0854 & Fumarate hydratase class II 1 & 3 & 11 \\
\hline CalB & PA0366 & $\begin{array}{c}\text { Probable coniferyl aldehyde } \\
\text { dehydrogenase }\end{array}$ & 9 & 25.0 \\
\hline DavT & PA0266 & $\begin{array}{c}\text { 5-aminovalerate aminotransferase } \\
\text { DavT }\end{array}$ & 4 & 13 \\
\hline Hcp1 & PA0085 & Protein Hcp1 & 3 & 21 \\
\hline GyrB & PA0004 & DNA gyrase subunit B & 8 & 11 \\
\hline DnaN & PA0002 & Beta sliding clamp & 6 & 20 \\
\hline TrxA & PA5240 & Thioredoxin & 2 & 21 \\
\hline WbjC & 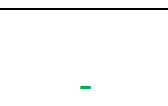 & $\begin{array}{l}\text { UDP-2-acetamido-2,6-beta-L- } \\
\text { arabino-hexul-4-ose reductase }\end{array}$ & 5 & 18 \\
\hline PilY1 & PA4554 & $\begin{array}{c}\text { Type IV pilus biogenesis factor } \\
\text { PilY1 }\end{array}$ & 11 & 12 \\
\hline
\end{tabular}


S2 Table: Proteins identified from axial ablations on transwell membrane insert grown biofilms. A comprehensive list of statistically significant $P$. aeruginosa proteins identified from three-day biofilms grown on transwell cell culture plate inserts. Proteins with blue fonts correspond to those that are higher abundance in the anoxic region compared to the oxic region, while proteins in red fonts are lower abundance in the anoxic region. The proteins without highlights are not statistically significant but meet the selection criteria (at least two unique peptides and $\geq 10 \%$ sequence coverage). The tabulated proteins are also portrayed on the volcano plot in Fig 6 .

\begin{tabular}{|c|c|c|c|c|c|c|c|}
\hline Protein & $\begin{array}{c}\text { KEGG } \\
\text { ID }\end{array}$ & Description of Protein & $\begin{array}{c}\text { Unique } \\
\text { Peptides }\end{array}$ & $\begin{array}{c}\begin{array}{c}\text { Sequence } \\
\text { Coverage } \\
(\%)\end{array} \\
\end{array}$ & $\begin{array}{c}\log _{2} \\
\left(\mathbf{X}_{\text {Anaerobic }} / \mathbf{X}_{\text {Aerobic }}\right)\end{array}$ & q-value & $\begin{array}{c}-\log _{10} \\
\text { (p-value) }\end{array}$ \\
\hline Icd & PA2623 & $\begin{array}{c}\text { Isocitrate } \\
\text { dehydrogenase } \\
\text { [NADP] }\end{array}$ & 26 & 62.7 & 4.09 & 0.18 & 0.84 \\
\hline $\mathrm{BraC}$ & PA1074 & $\begin{array}{l}\text { Leucine-, isoleucine-, } \\
\text { valine-, threonine-, and } \\
\text { alanine-binding protein }\end{array}$ & 18 & 70.0 & 3.87 & 0.08 & 1.37 \\
\hline SucD & PA1589 & $\begin{array}{l}\text { Succinate--CoA ligase } \\
\text { [ADP-forming] subunit } \\
\text { alpha }\end{array}$ & 13 & 61.7 & 3.85 & 0.08 & 1.32 \\
\hline LpdG & PA1587 & $\begin{array}{l}\text { Dihydrolipoyl } \\
\text { dehydrogenase }\end{array}$ & 21 & 60.5 & 3.65 & 0.11 & 1.09 \\
\hline AhpC & PA0139 & $\begin{array}{l}\text { Alkyl hydroperoxide } \\
\text { reductase C }\end{array}$ & 11 & 73.3 & 3.61 & 0.10 & 1.15 \\
\hline RplY & PA4671 & $\begin{array}{l}\text { 50S ribosomal protein } \\
\text { L25 }\end{array}$ & 12 & 79.9 & 3.58 & 0.00 & 3.36 \\
\hline RplV & PA4258 & $\begin{array}{l}\text { 50S ribosomal protein } \\
\text { L22 }\end{array}$ & 6 & 48.2 & 3.33 & 0.01 & 1.86 \\
\hline FusA & PA4266 & Elongation factor G 1 & 34 & 73.5 & 3.16 & 0.16 & 0.94 \\
\hline RpsA & PA3162 & $\begin{array}{l}\text { 30S ribosomal protein } \\
\text { S1 }\end{array}$ & 26 & 47.4 & 3.12 & 0.10 & 1.18 \\
\hline AnsB & PA1337 & $\begin{array}{l}\text { Glutaminase- } \\
\text { asparaginase }\end{array}$ & 12 & 51.7 & 3.09 & 0.00 & 3.29 \\
\hline HupB & PA1804 & $\begin{array}{l}\text { DNA-binding protein } \\
\text { HU-beta }\end{array}$ & 5 & 63.3 & 3.01 & 0.02 & 2.11 \\
\hline CarA & PA4758 & $\begin{array}{l}\text { Carbamoyl-phosphate } \\
\text { synthase small chain }\end{array}$ & 6 & 28.6 & 2.96 & 0.94 & 0.00 \\
\hline ArcA & PA5171 & Arginine deiminase & 23 & 66.3 & 2.96 & 0.02 & 1.97 \\
\hline EtfB & PA2952 & $\begin{array}{c}\text { Electron transfer } \\
\text { flavoprotein subunit } \\
\text { beta }\end{array}$ & 12 & 67.1 & 2.85 & 0.11 & 1.09 \\
\hline SodB & PA4366 & $\begin{array}{l}\text { Superoxide dismutase } \\
{[\mathrm{Fe}]}\end{array}$ & 6 & 40.9 & 2.76 & 0.92 & 0.00 \\
\hline PyrC' & PA0401 & $\begin{array}{c}\text { Dihydroorotase-like } \\
\text { protein }\end{array}$ & 6 & 19.6 & 2.65 & 0.85 & 0.00 \\
\hline
\end{tabular}




\begin{tabular}{|c|c|c|c|c|c|c|c|}
\hline AtpB & PA5560 & ATP synthase subunit a & 3 & 15.9 & 2.63 & 0.09 & 1.19 \\
\hline PurM & PA0945 & $\begin{array}{c}\text { Phosphoribosylformylg } \\
\text { lycinamidine cyclo- } \\
\text { ligase }\end{array}$ & 12 & 53.5 & 2.63 & 1.00 & 0.00 \\
\hline Tsf & PA3655 & Elongation factor Ts & 18 & 68.2 & 2.56 & 0.39 & 0.62 \\
\hline Gor & PA2025 & Glutathione reductase & 8 & 26.6 & 2.56 & 0.98 & 0.00 \\
\hline Psd & PA4957 & $\begin{array}{c}\text { Phosphatidylserine } \\
\text { decarboxylase } \\
\text { proenzyme }\end{array}$ & 5 & 23.2 & 2.55 & 1.00 & 0.00 \\
\hline Prs & PA4670 & $\begin{array}{l}\text { Ribose-phosphate } \\
\text { pyrophosphokinase }\end{array}$ & 13 & 57.2 & 2.53 & 0.01 & 1.89 \\
\hline AtpD & PA5554 & $\begin{array}{l}\text { ATP synthase subunit } \\
\text { beta }\end{array}$ & 22 & 69 & 2.53 & 0.04 & 1.53 \\
\hline MscL & PA4614 & $\begin{array}{l}\text { Large-conductance } \\
\text { mechanosensitive } \\
\text { channel }\end{array}$ & 3 & 28.5 & 2.46 & 0.00 & 2.63 \\
\hline ArgJ & PA4402 & $\begin{array}{c}\text { Arginine biosynthesis } \\
\text { bifunctional protein } \\
\text { ArgJ }\end{array}$ & 9 & 38.3 & 2.45 & 0.00 & 3.97 \\
\hline YidC & PA5568 & $\begin{array}{l}\text { Membrane protein } \\
\text { insertase YidC }\end{array}$ & 11 & 27.7 & 2.45 & 0.04 & 1.66 \\
\hline RapA & PA3308 & $\begin{array}{l}\text { RNA polymerase- } \\
\text { associated protein } \\
\text { RapA }\end{array}$ & 9 & 13.5 & 2.42 & 0.79 & 0.00 \\
\hline SpuD & PA0300 & $\begin{array}{l}\text { Putrescine-binding } \\
\text { periplasmic protein } \\
\text { SpuD }\end{array}$ & 9 & 31.9 & 2.40 & 0.01 & 2.48 \\
\hline FliC & PA1092 & B-type flagellin & 14 & 44.4 & 2.40 & 0.29 & 0.71 \\
\hline $\operatorname{ArgC}$ & PA0662 & $\begin{array}{l}\text { N-acetyl-gamma- } \\
\text { glutamyl-phosphate } \\
\text { reductase }\end{array}$ & 8 & 32.3 & 2.40 & 0.00 & 3.74 \\
\hline Dxs & PA4044 & $\begin{array}{l}\text { 1-deoxy-D-xylulose-5- } \\
\text { phosphate synthase }\end{array}$ & 6 & 15.8 & 2.39 & 1.00 & 0.00 \\
\hline $\operatorname{ArgG}$ & PA3525 & $\begin{array}{l}\text { Argininosuccinate } \\
\text { synthase }\end{array}$ & 12 & 37.5 & 2.36 & 0.00 & 3.06 \\
\hline Hcp1 & PA0085 & Protein Hcp1 & 6 & 46.9 & 2.35 & 0.73 & 0.00 \\
\hline FusB & PA2071 & Elongation factor G 2 & 13 & 40.7 & 2.32 & 0.77 & 0.00 \\
\hline PagL & PA4661 & $\begin{array}{c}\text { Lipid A deacylase } \\
\text { PagL }\end{array}$ & 6 & 45.1 & 2.32 & 0.05 & 1.58 \\
\hline RplA & PA4273 & $\begin{array}{l}\text { 50S ribosomal protein } \\
\text { L1 }\end{array}$ & 12 & 57.6 & 2.32 & 0.18 & 0.85 \\
\hline AtpG & PA5555 & $\begin{array}{l}\text { ATP synthase gamma } \\
\text { chain }\end{array}$ & 12 & 53.8 & 2.29 & 0.00 & 2.69 \\
\hline AtpA & PA5556 & $\begin{array}{l}\text { ATP synthase subunit } \\
\text { alpha }\end{array}$ & 5 & 43.8 & 2.26 & 0.16 & 0.94 \\
\hline
\end{tabular}




\begin{tabular}{|c|c|c|c|c|c|c|c|}
\hline Ppk2 & PA0141 & $\begin{array}{l}\text { Polyphosphate:ADP/G } \\
\text { DP phosphotransferase }\end{array}$ & 12 & 46.5 & 2.23 & 0.74 & 0.00 \\
\hline AstB & PA0899 & $\begin{array}{l}\mathrm{N} \text {-succinylarginine } \\
\text { dihydrolase }\end{array}$ & 8 & 22.8 & 2.17 & 1.00 & 0.00 \\
\hline AruC & PA0895 & $\begin{array}{c}\text { Succinylornithine } \\
\text { transaminase/acetylorni } \\
\text { thine aminotransferase }\end{array}$ & 17 & 60.3 & 2.12 & 0.01 & 2.44 \\
\hline FptA & PA4221 & $\begin{array}{l}\mathrm{Fe}(3+) \text {-pyochelin } \\
\text { receptor }\end{array}$ & 25 & 53.2 & 2.12 & 0.13 & 1.06 \\
\hline FumC1 & PA0854 & $\begin{array}{c}\text { Fumarate hydratase } \\
\text { class II } 1\end{array}$ & 11 & 40.3 & 2.04 & 0.75 & 0.00 \\
\hline GdhB & PA3068 & $\begin{array}{c}\text { NAD-specific } \\
\text { glutamate } \\
\text { dehydrogenase }\end{array}$ & 50 & 39.1 & 2.01 & 0.03 & 1.73 \\
\hline CysS & PA1795 & Cysteine--tRNA ligase & 12 & 31.3 & 2.00 & 1.00 & 0.00 \\
\hline SpuE & PA0301 & $\begin{array}{c}\text { Spermidine-binding } \\
\text { periplasmic protein } \\
\text { SpuE }\end{array}$ & 7 & 25.5 & 2.00 & 0.74 & 0.00 \\
\hline HemL & PA3977 & $\begin{array}{c}\text { Glutamate-1- } \\
\text { semialdehyde 2,1- } \\
\text { aminomutase }\end{array}$ & 9 & 32.1 & 1.99 & 1.00 & 0.00 \\
\hline GalU & PA2023 & $\begin{array}{l}\text { UTP--glucose-1- } \\
\text { phosphate } \\
\text { uridylyltransferase }\end{array}$ & 8 & 43.4 & 1.95 & 0.76 & 0.00 \\
\hline DavD & PA0265 & $\begin{array}{c}\text { Glutarate-semialdehyde } \\
\text { dehydrogenase }\end{array}$ & 13 & 39.8 & 1.91 & 0.02 & 2.33 \\
\hline PurA & PA4938 & $\begin{array}{l}\text { Adenylosuccinate } \\
\text { synthetase }\end{array}$ & 16 & 48.8 & 1.89 & 0.02 & 2.19 \\
\hline RplJ & PA4272 & $\begin{array}{l}\text { 50S ribosomal protein } \\
\text { L10 }\end{array}$ & 8 & 48.8 & 1.88 & 0.18 & 0.84 \\
\hline UbiG & PA3171 & $\begin{array}{c}\text { Ubiquinone } \\
\text { biosynthesis O- } \\
\text { methyltransferase }\end{array}$ & 6 & 39.7 & 1.88 & 0.87 & 0.00 \\
\hline GyrB & PA0004 & DNA gyrase subunit B & 20 & 35.5 & 1.87 & 0.73 & 0.00 \\
\hline IleS & PA4560 & $\begin{array}{l}\text { Isoleucine--tRNA } \\
\text { ligase }\end{array}$ & 16 & 24.1 & 1.87 & 0.89 & 0.00 \\
\hline PurH & PA4854 & $\begin{array}{l}\text { Bifunctional purine } \\
\text { biosynthesis protein } \\
\text { PurH }\end{array}$ & 11 & 27.5 & 1.86 & 0.08 & 1.35 \\
\hline Pnp & PA4740 & $\begin{array}{l}\text { Polyribonucleotide } \\
\text { nucleotidyltransferase }\end{array}$ & 26 & 50.8 & 1.85 & 0.08 & 1.31 \\
\hline $\mathrm{Pal}$ & PA0973 & $\begin{array}{c}\text { Peptidoglycan- } \\
\text { associated lipoprotein }\end{array}$ & 7 & 66.7 & 1.84 & 0.34 & 0.67 \\
\hline OprB & PA3186 & Porin B & 21 & 58.1 & 1.84 & 0.49 & 0.55 \\
\hline
\end{tabular}




\begin{tabular}{|c|c|c|c|c|c|c|c|}
\hline PA3286 & PA3286 & $\begin{array}{l}\text { Beta-ketodecanoyl- } \\
\text { [acyl-carrier-protein] } \\
\text { synthase }\end{array}$ & 8 & 37.1 & 1.83 & 0.78 & 0.00 \\
\hline DnaK & PA4761 & $\begin{array}{c}\text { Chaperone protein } \\
\text { DnaK }\end{array}$ & 26 & 63.9 & 1.81 & 0.50 & 0.54 \\
\hline $\begin{array}{l}\text { TufA; } \\
\text { TufB }\end{array}$ & PA4265 & Elongation factor $\mathrm{Tu}$ & 21 & 77.3 & 1.81 & 0.21 & 0.80 \\
\hline $\mathrm{Hpd}$ & PA0865 & $\begin{array}{c}4- \\
\text { hydroxyphenylpyruvate } \\
\text { dioxygenase }\end{array}$ & 12 & 45.9 & 1.80 & 0.00 & 2.70 \\
\hline PA2953 & PA2953 & $\begin{array}{l}\text { Electron transfer } \\
\text { flavoprotein- } \\
\text { ubiquinone } \\
\text { oxidoreductase } \\
\end{array}$ & 19 & 46.5 & 1.80 & 0.03 & 1.75 \\
\hline RplP & PA4256 & $\begin{array}{l}\text { 50S ribosomal protein } \\
\text { L16 }\end{array}$ & 5 & 40.1 & 1.79 & 0.01 & 2.44 \\
\hline MetZ & PA3107 & $\begin{array}{l}\text { O-succinylhomoserine } \\
\text { sulfhydrylase }\end{array}$ & 7 & 23.8 & 1.79 & 0.91 & 0.00 \\
\hline ArgB & PA5323 & Acetylglutamate kinase & 5 & 20.9 & 1.77 & 1.00 & 0.00 \\
\hline FumC2 & PA4470 & $\begin{array}{c}\text { Fumarate hydratase } \\
\text { class II } 2\end{array}$ & 11 & 32.5 & 1.77 & 0.86 & 0.00 \\
\hline MexB & PA0426 & $\begin{array}{l}\text { Multidrug resistance } \\
\text { protein MexB }\end{array}$ & 14 & 18.4 & 1.73 & 0.01 & 2.56 \\
\hline MetE & PA1927 & $\begin{array}{c}5- \\
\text { methyltetrahydropteroy } \\
\text { ltriglutamate- } \\
\text { homocysteine } \\
\text { methyltransferase }\end{array}$ & 18 & 27.8 & 1.68 & 0.02 & 2.06 \\
\hline PepA & PA3831 & $\begin{array}{c}\text { Cytosol } \\
\text { aminopeptidase }\end{array}$ & 19 & 50.9 & 1.66 & 0.02 & 2.00 \\
\hline $\mathrm{Cmk}$ & PA3163 & Cytidylate kinase & 4 & 25.3 & 1.62 & 1.00 & 0.00 \\
\hline GyrA & PA3168 & DNA gyrase subunit A & 14 & 20.8 & 1.62 & 0.00 & 3.69 \\
\hline $\mathrm{MmsB}$ & PA3569 & $\begin{array}{l}\text { 3-hydroxyisobutyrate } \\
\text { dehydrogenase }\end{array}$ & 5 & 20.1 & 1.60 & 0.96 & 0.00 \\
\hline ProS & PA0956 & Proline--tRNA ligase & 15 & 38.7 & 1.58 & 0.05 & 1.56 \\
\hline GlmS & PA5549 & $\begin{array}{c}\text { Glutamine--fructose-6- } \\
\text { phosphate } \\
\text { aminotransferase } \\
\text { [isomerizing] }\end{array}$ & 12 & 30.4 & 1.57 & 0.84 & 0.00 \\
\hline SecG & PA4747 & $\begin{array}{l}\text { Protein-export } \\
\text { membrane protein } \\
\text { SecG }\end{array}$ & 3 & 37.2 & 1.55 & 0.82 & 0.00 \\
\hline MaeA & PA3471 & $\begin{array}{l}\text { NAD-dependent malic } \\
\text { enzyme }\end{array}$ & 10 & 30.9 & 1.54 & 0.87 & 0.00 \\
\hline
\end{tabular}




\begin{tabular}{|c|c|c|c|c|c|c|c|}
\hline Anr & PA1544 & $\begin{array}{c}\text { Transcriptional } \\
\text { activator protein anr }\end{array}$ & 3 & 16.4 & 1.51 & 0.97 & 0.00 \\
\hline WbjC & - & $\begin{array}{l}\text { UDP-2-acetamido-2,6- } \\
\text { beta-L-arabino-hexul- } \\
\text { 4-ose reductase }\end{array}$ & 7 & 29.8 & 1.51 & 0.72 & 0.00 \\
\hline Eda & PA3181 & $\begin{array}{l}\text { 2-dehydro-3-deoxy- } \\
\text { phosphogluconate } \\
\text { aldolase }\end{array}$ & 5 & 26.4 & 1.49 & 0.08 & 1.39 \\
\hline AroB & PA5038 & $\begin{array}{l}\text { 3-dehydroquinate } \\
\text { synthase }\end{array}$ & 4 & 17.7 & 1.45 & 1.00 & 0.00 \\
\hline MmsA & PA3570 & $\begin{array}{l}\text { Methylmalonate- } \\
\text { semialdehyde } \\
\text { dehydrogenase } \\
\text { [acylating] }\end{array}$ & 12 & 34.6 & 1.44 & 0.96 & 0.00 \\
\hline OprD & PA0958 & Porin D & 13 & 37.7 & 1.42 & 0.84 & 0.38 \\
\hline $\mathrm{AlgC}$ & PA5322 & $\begin{array}{c}\text { Phosphomannomutase/ } \\
\text { phosphoglucomutase }\end{array}$ & 13 & 35.6 & 1.42 & 0.00 & 3.08 \\
\hline AguA & PA0292 & Agmatine deiminase & 3 & 13.6 & 1.41 & 1.00 & 0.00 \\
\hline Eco & PA2755 & Ecotin & 5 & 41.7 & 1.41 & 1.00 & 0.00 \\
\hline TyrS2 & PA0668 & $\begin{array}{l}\text { Tyrosine--tRNA ligase } \\
2 \\
\end{array}$ & 10 & 29.3 & 1.39 & 0.74 & 0.00 \\
\hline AcsA1 & PA0887 & $\begin{array}{l}\text { Acetyl-coenzyme A } \\
\text { synthetase } 1\end{array}$ & 23 & 55 & 1.39 & 0.22 & 0.78 \\
\hline HisA & PA5141 & $\begin{array}{c}\text { 1-(5-phosphoribosyl)- } \\
5-[(5- \\
\text { phosphoribosylamino }) \\
\text { methylideneamino] } \\
\text { imidazole-4- } \\
\text { carboxamide isomerase }\end{array}$ & 5 & 25.7 & 1.39 & 0.13 & 1.06 \\
\hline ValS & PA3834 & Valine--tRNA ligase & 24 & 30.8 & 1.38 & 0.18 & 0.83 \\
\hline SucC & PA1588 & $\begin{array}{l}\text { Succinate--CoA ligase } \\
\text { [ADP-forming] subunit } \\
\text { beta }\end{array}$ & 13 & 62.1 & 1.37 & 0.69 & 0.45 \\
\hline Efp & PA2851 & Elongation factor $\mathrm{P}$ & 6 & 33.5 & 1.35 & 0.02 & 2.17 \\
\hline RplQ & PA4237 & $\begin{array}{c}\text { 50S ribosomal protein } \\
\text { L17 }\end{array}$ & 5 & 49.6 & 1.34 & 1.00 & 0.00 \\
\hline $\mathrm{ClpB}$ & PA4542 & $\begin{array}{c}\text { Chaperone protein } \\
\text { ClpB }\end{array}$ & 35 & 55.4 & 1.33 & 0.03 & 1.78 \\
\hline MurD & PA4414 & $\begin{array}{c}\text { UDP-N- } \\
\text { acetylmuramoylalanine } \\
\text {--D-glutamate ligase }\end{array}$ & 5 & 12.3 & 1.31 & 0.80 & 0.00 \\
\hline AccD & PA3112 & $\begin{array}{l}\text { Acetyl-coenzyme A } \\
\text { carboxylase carboxyl } \\
\text { transferase subunit beta }\end{array}$ & 4 & 29.7 & 1.31 & 0.88 & 0.00 \\
\hline
\end{tabular}




\begin{tabular}{|c|c|c|c|c|c|c|c|}
\hline BamD & PA4545 & $\begin{array}{c}\text { Outer membrane } \\
\text { protein assembly factor } \\
\text { BamD } \\
\end{array}$ & 13 & 49 & 1.26 & 0.08 & 1.28 \\
\hline PA1579 & PA1579 & $\begin{array}{l}\text { Uncharacterized } \\
\text { protein PA1579 }\end{array}$ & 5 & 26.7 & 1.26 & 0.02 & 1.89 \\
\hline Pgk & PA0552 & $\begin{array}{c}\text { Phosphoglycerate } \\
\text { kinase }\end{array}$ & 15 & 51.7 & 1.25 & 0.03 & 1.71 \\
\hline $\mathrm{AccC}$ & PA4848 & Biotin carboxylase & 14 & 45.4 & 1.25 & 0.00 & 3.65 \\
\hline Def & PA0019 & Peptide deformylase & 3 & 21.4 & 1.24 & 0.73 & 0.00 \\
\hline DavT & PA0266 & $\begin{array}{c}\text { 5-aminovalerate } \\
\text { aminotransferase DavT }\end{array}$ & 14 & 52.1 & 1.24 & 0.08 & 1.35 \\
\hline HtpG & PA1596 & $\begin{array}{c}\text { Chaperone protein } \\
\text { HtpG }\end{array}$ & 36 & 66.6 & 1.22 & 1.00 & 0.28 \\
\hline HisG & PA4449 & $\begin{array}{c}\text { ATP } \\
\text { phosphoribosyltransfer } \\
\text { ase }\end{array}$ & 5 & 34.1 & 1.22 & 1.00 & 0.00 \\
\hline MetG & PA3482 & $\begin{array}{l}\text { Methionine--tRNA } \\
\text { ligase }\end{array}$ & 21 & 40.4 & 1.20 & 0.40 & 0.61 \\
\hline BamB & PA3800 & $\begin{array}{c}\text { Outer membrane } \\
\text { protein assembly factor } \\
\text { BamB }\end{array}$ & 10 & 41.8 & 1.20 & 0.79 & 0.00 \\
\hline Qor & PA0023 & $\begin{array}{c}\text { Quinone } \\
\text { oxidoreductase }\end{array}$ & 10 & 42.2 & 1.20 & 0.17 & 0.87 \\
\hline AcsA2 & PA4733 & $\begin{array}{l}\text { Acetyl-coenzyme A } \\
\text { synthetase } 2\end{array}$ & 11 & 29.3 & 1.19 & 0.40 & 0.62 \\
\hline SerC & PA3167 & $\begin{array}{c}\text { Phosphoserine } \\
\text { aminotransferase }\end{array}$ & 11 & 35.7 & 1.19 & 1.00 & 0.00 \\
\hline ThiG & PA0381 & Thiazole synthase & 4 & 22.3 & 1.18 & 1.00 & 0.00 \\
\hline SthA & PA2991 & $\begin{array}{l}\text { Soluble pyridine } \\
\text { nucleotide } \\
\text { transhydrogenase }\end{array}$ & 14 & 39.9 & 1.18 & 0.03 & 1.71 \\
\hline PA4395 & PA4395 & $\begin{array}{l}\text { UPF0234 protein } \\
\text { PA4395 }\end{array}$ & 11 & 50.9 & 1.16 & 0.08 & 1.29 \\
\hline FimW & PA4958 & $\begin{array}{l}\text { Cyclic-di-GMP } \\
\text { receptor FimW }\end{array}$ & 5 & 11.7 & 1.16 & 0.83 & 0.00 \\
\hline PurL & PA3763 & $\begin{array}{l}\text { Phosphoribosylformylg } \\
\text { lycinamidine synthase }\end{array}$ & 16 & 17.5 & 1.15 & 0.79 & 0.00 \\
\hline SurA & PA0594 & Chaperone SurA & 10 & 29.3 & 1.14 & 0.10 & 1.16 \\
\hline $\operatorname{ArgS}$ & PA5051 & Arginine--tRNA ligase & 2 & 27.8 & 1.14 & 0.02 & 2.02 \\
\hline $\mathrm{BkdB}$ & PA2249 & $\begin{array}{c}\text { Lipoamide } \\
\text { acyltransferase } \\
\text { component of branched- } \\
\text { chain alpha-keto acid } \\
\text { dehydrogenase complex }\end{array}$ & 6 & 15.9 & 1.12 & 0.77 & 0.00 \\
\hline
\end{tabular}




\begin{tabular}{|c|c|c|c|c|c|c|c|}
\hline ArcB & PA5172 & $\begin{array}{c}\text { Ornithine } \\
\text { carbamoyltransferase, } \\
\text { catabolic }\end{array}$ & 20 & 68.5 & 1.11 & 0.02 & 1.79 \\
\hline PckA & PA5192 & $\begin{array}{l}\text { Phosphoenolpyruvate } \\
\text { carboxykinase (ATP) }\end{array}$ & 2 & 49.9 & 1.08 & 0.05 & 1.63 \\
\hline ZipA & PA1528 & $\begin{array}{c}\text { Cell division protein } \\
\text { ZipA }\end{array}$ & 5 & 25.3 & 1.06 & 1.00 & 0.00 \\
\hline FabZ & PA3645 & $\begin{array}{l}\text { 3-hydroxyacyl-[acyl- } \\
\text { carrier-protein] } \\
\text { dehydratase FabZ }\end{array}$ & 4 & 37.7 & 1.03 & 1.00 & 0.00 \\
\hline FabG & PA2967 & $\begin{array}{l}\text { 3-oxoacyl-[acyl- } \\
\text { carrier-protein] } \\
\text { reductase FabG }\end{array}$ & 7 & 40.1 & 1.03 & 0.00 & 2.88 \\
\hline Mqo2 & PA4640 & $\begin{array}{c}\text { Probable } \\
\text { malate:quinone } \\
\text { oxidoreductase } 2\end{array}$ & 8 & 18.5 & 1.02 & 0.82 & 0.00 \\
\hline PyrE & PA5331 & $\begin{array}{l}\text { Orotate phosphori- } \\
\text { bosyltransferase }\end{array}$ & 6 & 35.7 & 1.01 & 1.00 & 0.00 \\
\hline AhcY & PA0432 & Adenosylhomocysteinase & 20 & 56.5 & 1.01 & 0.02 & 1.94 \\
\hline AtoB & PA2001 & $\begin{array}{c}\text { Acetyl-CoA } \\
\text { acetyltransferase }\end{array}$ & 8 & 32.8 & 0.98 & 0.76 & 0.00 \\
\hline PyrG & PA3637 & CTP synthase & 22 & 53 & 0.96 & 0.11 & 1.11 \\
\hline ExaA & PA1982 & $\begin{array}{l}\text { Quinoprotein ethanol } \\
\text { dehydrogenase } \\
\text { (cytochrome c) }\end{array}$ & 19 & 40.9 & 0.94 & 0.16 & 0.90 \\
\hline Edd & PA3194 & $\begin{array}{l}\text { Phosphogluconate } \\
\text { dehydratase }\end{array}$ & 15 & 39.5 & 0.93 & 0.01 & 2.50 \\
\hline LysS & PA3700 & Lysine--tRNA ligase & 23 & 49.1 & 0.89 & 0.02 & 2.09 \\
\hline RplU & PA4568 & $\begin{array}{l}\text { 50S ribosomal protein } \\
\text { L21 }\end{array}$ & 7 & 67 & 0.89 & 0.67 & 0.47 \\
\hline PilY1 & PA4554 & $\begin{array}{c}\text { Type IV pilus } \\
\text { biogenesis factor PilY1 }\end{array}$ & 20 & 25.4 & 0.86 & 0.02 & 1.93 \\
\hline Fmt & PA0018 & $\begin{array}{l}\text { Methionyl-tRNA } \\
\text { formyltransferase }\end{array}$ & 5 & 25.8 & 0.85 & 0.86 & 0.00 \\
\hline Pgl & PA3182 & $\begin{array}{c}6- \\
\text { phosphogluconolactonase }\end{array}$ & 5 & 29.4 & 0.82 & 0.08 & 1.26 \\
\hline PurC & PA1013 & $\begin{array}{c}\text { Phosphoribosylaminoi } \\
\text { midazole- } \\
\text { succinocarboxamide } \\
\text { synthase }\end{array}$ & 8 & 41.1 & 0.82 & 0.20 & 0.81 \\
\hline ThrC & PA3735 & Threonine synthase & 11 & 31.3 & 0.82 & 0.96 & 0.00 \\
\hline LepA & PA0767 & Elongation factor 4 & 6 & 12.5 & 0.80 & 1.00 & 0.00 \\
\hline Ggt & PA1338 & $\begin{array}{l}\text { Glutathione hydrolase } \\
\text { proenzyme }\end{array}$ & 8 & 20.3 & 0.79 & 0.75 & 0.00 \\
\hline
\end{tabular}




\begin{tabular}{|c|c|c|c|c|c|c|c|}
\hline NuoB & PA2638 & $\begin{array}{c}\text { NADH-quinone } \\
\text { oxidoreductase subunit } \\
\text { B } \\
\end{array}$ & 3 & 18.7 & 0.78 & 1.00 & 0.00 \\
\hline GlnS & PA1794 & $\begin{array}{c}\text { Glutamine--tRNA } \\
\text { ligase }\end{array}$ & 13 & 31.7 & 0.78 & 0.08 & 1.27 \\
\hline CheB1 & PA1459 & $\begin{array}{c}\text { Protein-glutamate } \\
\text { methylesterase/protein- } \\
\text { glutamine glutaminase } \\
1\end{array}$ & 6 & 25 & 0.76 & 1.00 & 0.00 \\
\hline RpsD & PA4239 & $\begin{array}{l}\text { 30S ribosomal protein } \\
\text { S4 }\end{array}$ & 13 & 48.5 & 0.75 & 0.05 & 1.61 \\
\hline $\mathrm{ArgH}$ & PA5263 & $\begin{array}{c}\text { Argininosuccinate } \\
\text { lyase }\end{array}$ & 10 & 29.1 & 0.74 & 0.92 & 0.00 \\
\hline PheA & PA3166 & $\begin{array}{c}\text { Bifunctional } \\
\text { chorismate } \\
\text { mutase/prephenate } \\
\text { dehydratase }\end{array}$ & 6 & 21.9 & 0.73 & 0.78 & 0.00 \\
\hline Glk & PA3193 & Glucokinase & 7 & 32.6 & 0.73 & 0.87 & 0.00 \\
\hline MexA & PA0425 & $\begin{array}{l}\text { Multidrug resistance } \\
\text { protein MexA }\end{array}$ & 12 & 52.2 & 0.72 & 0.05 & 0.20 \\
\hline GroEL & PA4385 & $60 \mathrm{kDa}$ chaperonin & 19 & 55.9 & 0.71 & 1.00 & 0.00 \\
\hline KdsA & PA3636 & $\begin{array}{c}\text { 2-dehydro-3- } \\
\text { deoxyphosphooctonate } \\
\text { aldolase }\end{array}$ & 7 & 25.3 & 0.71 & 1.00 & 0.69 \\
\hline $\mathrm{RpsP}$ & PA3745 & $\begin{array}{l}\text { 30S ribosomal protein } \\
\text { S16 }\end{array}$ & 3 & 48.2 & 0.69 & 0.31 & 0.99 \\
\hline PpsA & PA1770 & $\begin{array}{l}\text { Phosphoenolpyruvate } \\
\text { synthase }\end{array}$ & 32 & 51.2 & 0.68 & 0.14 & 0.00 \\
\hline SpeE2 & PA4774 & $\begin{array}{c}\text { Polyamine } \\
\text { aminopropyltransferase } \\
2 \\
\end{array}$ & 6 & 25.5 & 0.68 & 0.82 & 0.00 \\
\hline $\mathrm{RdgC}$ & PA3263 & $\begin{array}{l}\text { Recombination- } \\
\text { associated protein } \\
\mathrm{RdgC}\end{array}$ & 11 & 50.7 & 0.67 & 1.00 & 0.00 \\
\hline $\mathrm{SpuC}$ & PA0299 & $\begin{array}{l}\text { Putrescine--pyruvate } \\
\text { aminotransferase }\end{array}$ & 9 & 35.1 & 0.66 & 0.74 & 0.00 \\
\hline OprF & PA1777 & $\begin{array}{l}\text { Outer membrane porin } \\
\mathrm{F}\end{array}$ & 18 & 67.1 & 0.65 & 1.00 & 0.18 \\
\hline GlyS & PA0008 & $\begin{array}{l}\text { Glycine--tRNA ligase } \\
\text { beta subunit }\end{array}$ & 14 & 28.9 & 0.65 & 0.10 & 1.16 \\
\hline RibB & PA4054 & $\begin{array}{c}\text { 3,4-dihydroxy-2- } \\
\text { butanone 4-phosphate } \\
\text { synthase }\end{array}$ & 7 & 27.7 & 0.64 & 0.98 & 0.31 \\
\hline PanB2 & PA4729 & $\begin{array}{l}\text { 3-methyl-2-oxobutanoate } \\
\text { hydroxymethyltransferase } \\
2\end{array}$ & 3 & 14.3 & 0.63 & 0.89 & 0.00 \\
\hline
\end{tabular}




\begin{tabular}{|c|c|c|c|c|c|c|c|}
\hline $\mathrm{Gln} \mathrm{A}$ & PA5119 & Glutamine synthetase & 17 & 44.6 & 0.62 & 0.92 & 0.33 \\
\hline $\mathrm{CalB}$ & PA0366 & $\begin{array}{l}\text { Probable coniferyl } \\
\text { aldehyde } \\
\text { dehydrogenase }\end{array}$ & 13 & 37.8 & 0.62 & 0.04 & 1.64 \\
\hline ProA & PA4007 & $\begin{array}{l}\text { Gamma-glutamyl } \\
\text { phosphate reductase }\end{array}$ & 10 & 30.9 & 0.62 & 1.00 & 0.00 \\
\hline PctB & PA4310 & $\begin{array}{l}\text { Methyl-accepting } \\
\text { chemotaxis protein } \\
\text { PctB }\end{array}$ & 3 & 29.7 & 0.62 & 0.80 & 0.00 \\
\hline $\operatorname{TrpS}$ & PA4439 & $\begin{array}{c}\text { Tryptophan--tRNA } \\
\text { ligase }\end{array}$ & 5 & 17.4 & 0.60 & 0.80 & 0.00 \\
\hline NusG & PA4275 & $\begin{array}{c}\text { Transcription } \\
\text { termination/antitermina } \\
\text { tion protein NusG }\end{array}$ & 5 & 35 & 0.60 & 0.02 & 1.98 \\
\hline GuaA & PA3769 & $\begin{array}{c}\text { GMP synthase } \\
\text { [glutamine- } \\
\text { hydrolyzing] }\end{array}$ & 22 & 55.8 & 0.59 & 0.00 & 2.76 \\
\hline TrpE & PA0609 & $\begin{array}{l}\text { Anthranilate synthase } \\
\text { component } 1\end{array}$ & 11 & 32.1 & 0.58 & 0.99 & 0.00 \\
\hline RpoB & PA4270 & $\begin{array}{l}\text { DNA-directed RNA } \\
\text { polymerase subunit } \\
\text { beta }\end{array}$ & 64 & 54.9 & 0.58 & 1.00 & 0.25 \\
\hline PilJ & PA0411 & Protein PilJ & 15 & 30.2 & -0.58 & 0.08 & 1.29 \\
\hline PctA & PA4309 & $\begin{array}{l}\text { Methyl-accepting } \\
\text { chemotaxis protein } \\
\text { PctA }\end{array}$ & 7 & 37.8 & -0.61 & 0.62 & 0.49 \\
\hline RpsF & PA4935 & $\begin{array}{l}\text { 30S ribosomal protein } \\
\text { S6 }\end{array}$ & 4 & 25.9 & -0.62 & 1.00 & 0.00 \\
\hline RpsQ & PA4254 & $\begin{array}{l}\text { 30S ribosomal protein } \\
\text { S17 }\end{array}$ & 4 & 42 & -0.62 & 0.18 & 0.83 \\
\hline AceF & PA5016 & $\begin{array}{c}\text { Dihydrolipoyllysine- } \\
\text { residue } \\
\text { acetyltransferase } \\
\text { component of pyruvate } \\
\text { dehydrogenase } \\
\text { complex }\end{array}$ & 22 & 48.6 & -0.63 & 0.15 & 0.94 \\
\hline InfC & PA2743 & $\begin{array}{l}\text { Translation initiation } \\
\text { factor IF-3 }\end{array}$ & 8 & 55.2 & -0.64 & 0.43 & 0.59 \\
\hline AspS & PA0963 & $\begin{array}{c}\text { Aspartate-- } \\
\text { tRNA(Asp/Asn) ligase }\end{array}$ & 12 & 38.4 & -0.67 & 0.02 & 2.25 \\
\hline $\mathrm{BraF}$ & PA1071 & $\begin{array}{l}\text { High-affinity branched- } \\
\text { chain amino acid } \\
\text { transport ATP-binding } \\
\text { protein BraF } \\
\end{array}$ & 8 & 41.2 & -0.67 & 0.98 & 0.00 \\
\hline PA3647 & PA3647 & Skp-like protein & 3 & 24.4 & -0.67 & 0.79 & 0.00 \\
\hline
\end{tabular}




\begin{tabular}{|c|c|c|c|c|c|c|c|}
\hline LpxC & PA4406 & $\begin{array}{l}\text { UDP-3-O-acyl-N- } \\
\text { acetylglucosamine } \\
\text { deacetylase }\end{array}$ & 11 & 40.3 & -0.67 & 0.05 & 1.51 \\
\hline MurC & PA4411 & $\begin{array}{c}\text { UDP-N- } \\
\text { acetylmuramate--L- } \\
\text { alanine ligase }\end{array}$ & 5 & 14.4 & -0.69 & 1.00 & 0.00 \\
\hline IlvD & PA0353 & $\begin{array}{l}\text { Dihydroxy-acid } \\
\text { dehydratase }\end{array}$ & 12 & 31.7 & -0.71 & 1.00 & 0.00 \\
\hline HldE & PA4996 & $\begin{array}{c}\text { Bifunctional protein } \\
\text { HldE }\end{array}$ & 6 & 15.9 & -0.71 & 1.00 & 0.00 \\
\hline $\mathrm{Hfq}$ & PA4944 & $\begin{array}{l}\text { RNA-binding protein } \\
\mathrm{Hfq}\end{array}$ & 6 & 75.6 & -0.71 & 1.00 & 0.00 \\
\hline Ndk & PA3807 & $\begin{array}{l}\text { Nucleoside diphosphate } \\
\text { kinase }\end{array}$ & 6 & 49 & -0.71 & 0.67 & 0.47 \\
\hline $\mathrm{RpmC}$ & PA4255 & $\begin{array}{l}\text { 50S ribosomal protein } \\
\text { L29 }\end{array}$ & 3 & 60.3 & -0.73 & 1.00 & 0.00 \\
\hline RpsE & PA4246 & $\begin{array}{l}\text { 30S ribosomal protein } \\
\text { S5 }\end{array}$ & 6 & 50 & -0.74 & 0.16 & 0.90 \\
\hline $\mathrm{Fba}$ & PA0555 & $\begin{array}{c}\text { Fructose-bisphosphate } \\
\text { aldolase }\end{array}$ & 12 & 49.2 & -0.75 & 0.15 & 0.97 \\
\hline RpsB & PA3656 & $\begin{array}{l}\text { 30S ribosomal protein } \\
\text { S2 }\end{array}$ & 11 & 57.3 & -0.76 & 0.31 & 0.69 \\
\hline AtpF & PA5558 & ATP synthase subunit b & 10 & 62.8 & -0.79 & 0.01 & 1.85 \\
\hline AotP & PA0892 & $\begin{array}{c}\text { Arginine/ornithine } \\
\text { transport ATP-binding } \\
\text { protein AotP }\end{array}$ & 5 & 20.9 & -0.79 & 1.00 & 0.00 \\
\hline GapA & PA3195 & $\begin{array}{c}\text { Glyceraldehyde-3- } \\
\text { phosphate } \\
\text { dehydrogenase-like } \\
\text { protein }\end{array}$ & 16 & 49 & -0.81 & 0.02 & 2.11 \\
\hline ThrS & PA2744 & $\begin{array}{c}\text { Threonine--tRNA } \\
\text { ligase }\end{array}$ & 21 & 39.5 & -0.83 & 0.04 & 1.53 \\
\hline DnaJ & PA4760 & $\begin{array}{l}\text { Chaperone protein } \\
\text { DnaJ }\end{array}$ & 13 & 35 & -0.86 & 1.00 & 0.00 \\
\hline PasP & PA0423 & $\begin{array}{l}\text { UPF0312 protein } \\
\text { PA0423 }\end{array}$ & 8 & 55.5 & -0.86 & 1.00 & 0.00 \\
\hline $\mathrm{NqrF}$ & PA2994 & $\begin{array}{l}\mathrm{Na}(+) \text {-translocating } \\
\mathrm{NADH} \text {-quinone } \\
\text { reductase subunit } \mathrm{F}\end{array}$ & 9 & 24.1 & -0.89 & 0.88 & 0.00 \\
\hline Ppx & PA5241 & Exopolyphosphatase & 7 & 18.8 & -0.90 & 0.72 & 0.00 \\
\hline ArcC & PA5173 & Carbamate kinase & 12 & 42.9 & -0.91 & 0.08 & 1.24 \\
\hline Adk & PA3686 & Adenylate kinase & 13 & 59.1 & -0.93 & 0.06 & 1.42 \\
\hline $\mathrm{RplC}$ & PA4263 & $\begin{array}{c}\text { 50S ribosomal protein } \\
\text { L3 }\end{array}$ & 7 & 35.1 & -0.94 & 0.24 & 0.76 \\
\hline
\end{tabular}




\begin{tabular}{|c|c|c|c|c|c|c|c|}
\hline RplO & PA4244 & $\begin{array}{l}\text { 50S ribosomal protein } \\
\text { L15 }\end{array}$ & 6 & 45.1 & -0.96 & 0.06 & 1.42 \\
\hline RpsG & PA4267 & $\begin{array}{l}\text { 30S ribosomal protein } \\
\text { S7 }\end{array}$ & 11 & 54.5 & -0.97 & 0.16 & 0.91 \\
\hline Pgi & PA4732 & $\begin{array}{l}\text { Glucose-6-phosphate } \\
\text { isomerase }\end{array}$ & 9 & 21.8 & -0.98 & 1.00 & 0.00 \\
\hline PheT & PA2739 & $\begin{array}{l}\text { Phenylalanine--tRNA } \\
\text { ligase beta subunit }\end{array}$ & 16 & 32.4 & -1.03 & 0.78 & 0.00 \\
\hline Ssb & PA4232 & $\begin{array}{l}\text { Single-stranded DNA- } \\
\text { binding protein }\end{array}$ & 8 & 63 & -1.05 & 0.14 & 0.99 \\
\hline ClpX & PA1802 & $\begin{array}{l}\text { ATP-dependent Clp } \\
\text { protease ATP-binding } \\
\text { subunit ClpX }\end{array}$ & 12 & 35 & -1.08 & 1.00 & 0.00 \\
\hline $\mathrm{RpsH}$ & PA4249 & $\begin{array}{c}\text { 30S ribosomal protein } \\
\text { S8 }\end{array}$ & 7 & 50.8 & -1.08 & 0.01 & 1.89 \\
\hline RpsJ & PA4264 & $\begin{array}{c}\text { 30S ribosomal protein } \\
\text { S10 }\end{array}$ & 3 & 34 & -1.09 & 0.06 & 1.42 \\
\hline GroES & PA4386 & $10 \mathrm{kDa}$ chaperonin & 1 & 17.5 & -1.09 & 1.00 & 0.00 \\
\hline RplN & PA4253 & $\begin{array}{l}\text { 50S ribosomal protein } \\
\text { L14 }\end{array}$ & 6 & 47.5 & -1.10 & 1.00 & 0.00 \\
\hline PilQ & PA5040 & $\begin{array}{c}\text { Fimbrial assembly } \\
\text { protein PilQ }\end{array}$ & 12 & 22.1 & -1.11 & 0.30 & 0.69 \\
\hline EstA & PA5112 & Esterase EstA & 9 & 15.9 & -1.11 & 1.00 & 0.00 \\
\hline RpsM & PA4241 & $\begin{array}{l}\text { 30S ribosomal protein } \\
\text { S13 }\end{array}$ & 8 & 65.3 & -1.13 & 0.05 & 1.55 \\
\hline BkdA1 & PA2247 & $\begin{array}{c}\text { 2-oxoisovalerate } \\
\text { dehydrogenase subunit } \\
\text { alpha }\end{array}$ & 5 & 16.8 & -1.15 & 0.77 & 0.00 \\
\hline AtpH & PA5557 & $\begin{array}{c}\text { ATP synthase subunit } \\
\text { delta }\end{array}$ & 5 & 27.5 & -1.16 & 0.17 & 0.89 \\
\hline GltX & PA3134 & $\begin{array}{l}\text { Glutamate--tRNA } \\
\text { ligase }\end{array}$ & 6 & 19.8 & -1.22 & 0.88 & 0.00 \\
\hline RplB & PA4260 & $\begin{array}{c}\text { 50S ribosomal protein } \\
\text { L2 }\end{array}$ & 14 & 53.5 & -1.22 & 0.14 & 0.99 \\
\hline TatA & PA5068 & $\begin{array}{l}\text { Sec-independent } \\
\text { protein translocase } \\
\text { protein TatA }\end{array}$ & 3 & 53.7 & -1.26 & 1.00 & 0.00 \\
\hline PheS & PA2740 & $\begin{array}{l}\text { Phenylalanine--tRNA } \\
\text { ligase alpha subunit }\end{array}$ & 12 & 34.9 & -1.29 & 0.89 & 0.00 \\
\hline TpiA & PA4748 & $\begin{array}{l}\text { Triosephosphate } \\
\text { isomerase }\end{array}$ & 5 & 45.8 & -1.34 & 1.00 & 0.00 \\
\hline LysA & PA5277 & $\begin{array}{l}\text { Diaminopimelate } \\
\text { decarboxylase }\end{array}$ & 8 & 26.5 & -1.34 & 0.99 & 0.00 \\
\hline GlpK2 & PA3582 & Glycerol kinase 2 & 10 & 22.6 & -1.36 & 0.05 & 1.51 \\
\hline
\end{tabular}




\begin{tabular}{|c|c|c|c|c|c|c|c|}
\hline HmgA & PA2009 & $\begin{array}{l}\text { Homogentisate } 1,2- \\
\text { dioxygenase }\end{array}$ & 7 & 20.4 & -1.37 & 1.00 & 0.00 \\
\hline $\mathrm{SecY}$ & PA4243 & $\begin{array}{c}\text { Protein translocase } \\
\text { subunit SecY }\end{array}$ & 5 & 13.6 & -1.39 & 0.80 & 0.00 \\
\hline Frr & PA3653 & $\begin{array}{l}\text { Ribosome-recycling } \\
\text { factor }\end{array}$ & 7 & 42.7 & -1.39 & 1.00 & 0.00 \\
\hline ClpV1 & PA0090 & $\mathrm{AAA}+\mathrm{ATPase}$ ClpV1 & 8 & 13 & -1.41 & 0.73 & 0.00 \\
\hline RpsL & PA4268 & $\begin{array}{l}\text { 30S ribosomal protein } \\
\text { S12 }\end{array}$ & 4 & 43.9 & -1.42 & 1.00 & 0.00 \\
\hline LeuA & PA3792 & $\begin{array}{l}\text { 2-isopropylmalate } \\
\text { synthase }\end{array}$ & 13 & 39.7 & -1.46 & 1.00 & 0.00 \\
\hline Gap & PA3195 & $\begin{array}{c}\text { Glyceraldehyde-3- } \\
\text { phosphate } \\
\text { dehydrogenase }\end{array}$ & 14 & 55.7 & -1.55 & 0.03 & 1.71 \\
\hline PurD & PA4855 & $\begin{array}{c}\text { Phosphoribosylamine-- } \\
\text { glycine ligase }\end{array}$ & 6 & 20.3 & -1.58 & 0.82 & 0.00 \\
\hline GlyA2 & PA4602 & $\begin{array}{c}\text { Serine } \\
\text { hydroxymethyltransfer } \\
\text { ase } 3 \\
\end{array}$ & 12 & 45.8 & -1.59 & 0.05 & 1.44 \\
\hline RpmG & PA5315 & $\begin{array}{l}\text { 50S ribosomal protein } \\
\text { L33 }\end{array}$ & 2 & 43.1 & -1.64 & 0.04 & 1.54 \\
\hline RplR & PA4247 & $\begin{array}{l}\text { 50S ribosomal protein } \\
\text { L18 }\end{array}$ & 7 & 51.7 & -1.64 & 0.05 & 1.51 \\
\hline RpsK & PA4240 & $\begin{array}{l}\text { 30S ribosomal protein } \\
\text { S11 }\end{array}$ & 4 & 41.9 & -1.67 & 0.02 & 1.79 \\
\hline $\mathrm{MrcA}$ & PA5045 & $\begin{array}{l}\text { Penicillin-binding } \\
\text { protein 1A }\end{array}$ & 9 & 12.7 & -1.72 & 0.86 & 0.00 \\
\hline Tpx & PA2532 & Thiol peroxidase & 6 & 55.8 & -1.74 & 0.91 & 0.00 \\
\hline RplM & PA4433 & $\begin{array}{l}\text { 50S ribosomal protein } \\
\text { L13 }\end{array}$ & 5 & 54.2 & -1.79 & 0.10 & 1.14 \\
\hline RplT & PA2741 & $\begin{array}{l}\text { 50S ribosomal protein } \\
\text { L20 }\end{array}$ & 3 & 22.9 & -1.80 & 1.00 & 0.00 \\
\hline AceA & PA2634 & Isocitrate lyase & 11 & 24.5 & -1.84 & 0.04 & 1.66 \\
\hline $\mathrm{RpsS}$ & PA4259 & $\begin{array}{l}\text { 30S ribosomal protein } \\
\text { S19 }\end{array}$ & 3 & 28.6 & -1.86 & 0.04 & 1.61 \\
\hline PrfA & PA4665 & $\begin{array}{l}\text { Peptide chain release } \\
\text { factor } 1\end{array}$ & 3 & 11.9 & -1.89 & 1.00 & 0.00 \\
\hline SelD & PA1642 & $\begin{array}{c}\text { Selenide, water } \\
\text { dikinase }\end{array}$ & 4 & 16.6 & -1.90 & 0.76 & 0.00 \\
\hline DnaK & PA4761 & $\begin{array}{c}\text { Chaperone protein } \\
\text { DnaK }\end{array}$ & 3 & 19 & -1.92 & 0.06 & 1.40 \\
\hline Pta & PA0835 & $\begin{array}{c}\text { Phosphate } \\
\text { acetyltransferase }\end{array}$ & 9 & 20.2 & -1.93 & 0.75 & 0.00 \\
\hline
\end{tabular}




\begin{tabular}{|c|c|c|c|c|c|c|c|}
\hline UbiE & PA5063 & $\begin{array}{c}\text { Ubiquinone/menaquino } \\
\text { ne biosynthesis C- } \\
\text { methyltransferase UbiE }\end{array}$ & 10 & 49.2 & -1.94 & 1.00 & 0.00 \\
\hline GcvP1 & PA2445 & $\begin{array}{c}\text { Glycine dehydrogenase } \\
\text { (decarboxylating) 1 }\end{array}$ & 10 & 17.7 & -1.94 & 0.78 & 0.00 \\
\hline HemN & PA1546 & $\begin{array}{c}\text { Oxygen-independent } \\
\text { coproporphyrinogen III } \\
\text { oxidase }\end{array}$ & 7 & 22.2 & -1.98 & 0.91 & 0.00 \\
\hline ArgF & PA3537 & $\begin{array}{c}\text { Ornithine } \\
\text { carbamoyltransferase, } \\
\text { anabolic }\end{array}$ & 5 & 23 & -2.21 & 1.00 & 0.00 \\
\hline RpmD & PA4245 & $\begin{array}{c}50 \text { S ribosomal protein } \\
\text { L30 }\end{array}$ & 2 & 25.9 & -2.26 & 1.00 & 0.00 \\
\hline RplL & PA4271 & $\begin{array}{c}50 \text { r ribosomal protein } \\
\text { L7/L12 }\end{array}$ & 3 & 19.7 & -2.84 & 1.00 & 0.00 \\
\hline
\end{tabular}

